Institute for Research on Poverty

Discussion Paper no. 1056-95

Take the Money and Run:

Economic Segregation in U.S. Metropolitan Areas

\author{
Paul A. Jargowsky \\ School of Social Sciences \\ University of Texas at Dallas
}

January 1995

This research was supported by a grant to the Institute for Research on Poverty from the Office of the Assistant Secretary for Planning and Evaluation, U.S. Department of Health and Human Services. I am grateful for comments on earlier drafts of this paper from Kurt Beron, Maria Cancian, Chris Desai, George Farkas, Janet Gamble, Robert Hauser, Don Hicks, Ron Mincy, Steven Sandell, Wim Vijverberg, and the participants in the IRP/HHS Research Conference (5/13/94). However, the author alone is responsible for the views expressed and any errors of fact or interpretation. 


\begin{abstract}
Compared to racial segregation, economic segregation has received little attention in recent empirical literature. Yet a heated debate has arisen concerning Wilson's hypothesis (1987) that increasing economic segregation plays a role in the formation of urban ghettos. This paper presents a methodological critique of the measure of economic segregation used by Massey and Eggers (1990) and finds that it confounds changes in the income distribution with spatial changes. I develop a "pure" measure of economic segregation and present findings on all U.S. metropolitan areas from 1970 to 1990. There have been steady increases in economic segregation for whites, blacks, and Hispanics in both the 1970s and 1980s, but the increases have been particularly large and widespread for blacks and Hispanics in the 1980s. The causes of these changes are explored in a reduced form, fixed-effects model. Social distance theory and structural economic transformations do affect economic segregation, but the large increases in economic segregation among minorities in the 1980s cannot be fully explained within the model. These rapid increases in economic segregation, especially in the context of recent, albeit small, declines in racial segregation, have important implications for urban policy, poverty policy, and the stability of urban communities.
\end{abstract}




\section{Take the Money and Run: Economic Segregation in U.S. Metropolitan Areas}

Racial segregation in the United States has been declining since 1970, but the decreases have been so slow that segregation of African Americans is still very high (Farley and Frey 1994). At the same time, economic inequality has been increasing since 1979, if not before (U.S. Bureau of the Census 1992, 1993). Both phenomena have been extensively documented. A third dimension of socioeconomic differentiation has received much less attention in recent years: economic segregation, i.e., the spatial segregation of households by income or social class. The relative dearth of recent studies in this area is surprising, in light of the importance ascribed to economic segregation by William Julius Wilson in his classic work, The Truly Disadvantaged (1987).

In this paper I document the fact that economic segregation has been increasing, not only among blacks, as Wilson alleges, but also within all major racial and ethnic groups, although the increases were largest for blacks and Hispanics in the 1980s. Moreover, the phenomenon is incredibly widespread, affecting virtually every metropolitan area in the United States. I also develop a causal model which, though clearly incomplete, suggests that the rapid increases in economic segregation among minorities represent a dramatic break from the pattern of previous decades. In other words, the factors which explain the changes in economic segregation for all groups over the 1970 to 1980 period consistently underpredict the changes for minorities in the 1980 to 1990 period. The breakdown of the 1970-1980 model represents a fundamental change in the processes that generate economic segregation. Understanding the causes of these changes, I would argue, has become a prerequisite to effective analysis of urban policies and programs. 


\section{ECONOMIC SEGREGATION AND ASSIMILATION}

A rich literature exists on the interrelationship of racial and economic segregation. Much of this literature can be traced to the classic paper by Park, who predicted that "successful individuals [of minority groups] move out and eventually find their places" so that "changes of economic and social status ... tend to be registered in changes of location" (1926: 9). More generally, Park argued that "social relations are ... inevitably correlated with spatial relations; ... physical distances . . are, or seem to be, the indexes of social distances" (18). Subsequent research has followed up on two related but conceptually distinct hypotheses stemming from this work: the first is the "social distance" hypothesis and the second is the "assimilation" hypothesis (Massey 1981: 642-643). According to the social distance hypothesis, racial or ethnic segregation is "positively associated with differences between groups" (642). The assimilation hypothesis states that better-off strata within a minority group will translate individual gains into spatial assimilation.

If the assimilation hypothesis is correct, then the degree of racial segregation should differ among social classes within a minority group. And it follows that higher-status members of the minority group will become more segregated from lower-status members of their own group as they become assimilated. Erbe (1975) addressed the issue of the socioeconomic segregation by income within racial groups. Responding to Kantrowitz, who found that "the better off black is as separated from the poorer black residentially as the better off white is from the poor white" (Kantrowitz 1973: v), ${ }^{1}$ Erbe argued that Kantrowitz's use of the index of dissimilarity (D) to measure economic segregation is inadequate because the index is insensitive to the relative proportions of lower-, middle-, and upper-class individuals in each group. She argued that "intergroup contact" is "a function both of residential segregation of populations and their relative size in the total population" (1975: 803).

Erbe favored the use of a measure of "asymmetric intergroup contact," more commonly known as the exposure index $\left(\mathrm{P}^{*}\right)$, which for two groups gives the average probability of contact of members of 
one group with members of the other. Using Chicago census data, Erbe found that the indices of dissimilarity by various measures of social class within racial groups differed little between whites and blacks. In contrast, exposure measures showed that higher-status blacks were far more likely to come into contact with lower-status members of their racial group than whites. Her conclusion:

Middle-class blacks are not randomly distributed throughout the ghetto and thus are segregated from the black lower class in this sense. Nevertheless they live in much closer propinquity with the lower class than do middle-class whites, simply because the black lower class is proportionally larger than the white lower class. To the extent that neighborhoods are the functional locus of many institutions, most especially schools, this is of great consequence.... In particular, it may be one factor in accounting for the low degree of occupational inheritance between high-status black fathers and their sons and the high degree of intergenerational downward mobility among blacks compared to whites (1975: 803).

How strange this quote sounds today, when the concern has been turned on its head: Wilson (1987) argues that the out-migration of the black middle class has resulted in the social isolation of the innercity black poor, with attendant "concentration effects."

Erbe's results demonstrated that one must distinguish between measures of economic segregation that are conditioned on income distribution and those that are not. Each type of measure has a value, but they answer different questions. If the incomes of all black households were to rise by a fixed amount, and nobody moved, the $\mathrm{P}^{*}$ index measuring contact with persons in poverty would change a great deal because there would be less black poverty to be exposed to. Assuming no changes in the classifications of families by social class, the index of dissimilarity would not change, since no one had moved. ${ }^{2}$ Thus, the exposure measure would accurately indicate that blacks were less likely to come into residential contact with poor persons, while the index of dissimilarity would correctly indicate that the degree of sorting by social class had not changed.

Farley (1977) also examined the interactions of racial and economic segregation. In part of his analysis, Farley applied the index of dissimilarity to years of education completed. He broke education into ten categories and calculated the 45 pair-wise indices of dissimilarity among them. He also 
calculated the dissimilarity of each group from all other groups. Farley found that the level of social class segregation was generally low relative to racial segregation, that the pattern of social class segregation among blacks and whites was quite similar, and that racial segregation was nearly constant across levels of social class. Taken together, these findings imply that racial segregation is not a product of economic segregation. ${ }^{3}$

Massey summarized the large body of empirical work on the social distance and assimilation hypotheses as follows: "In general, social distance is highly correlated with residential dissimilarity between particular ethnic groups [citations omitted]. In contrast, the assimilation hypothesis has not received consistent support" (1981: 643). Massey attributed some of this lack of support for the assimilation hypothesis to the use of "indirect standardization" in much of the literature. He argued that direct standardization, i.e., examining the index of dissimilarity between ethnic groups at fixed levels of social status, is preferable when possible. Studies employing the latter technique, such as Farley's study cited above, are more supportive of assimilation for Hispanics, but not for blacks (Massey 1981: Figure $1)$.

While much more could be said, for the purposes of this study there are several substantive conclusions to be drawn from the literature. First, racial segregation is far more complete than social class segregation; neighborhoods tend to be heterogeneous by income even as they are highly segregated by race and ethnicity. Second, although social distance is useful in predicting the crosssectional pattern of segregation, the prediction of residential assimilation following from economic advancement has not been supported for blacks, again highlighting the persistence of racial segregation.

Finally, racial segregation is not an artifact of economic segregation: the primary organizing principle of the metropolis is race/ethnicity, not social class. Kain concluded that "virtually every systematic study has concluded that black and white differences in income and other socioeconomic 
variables account for very little of the current and past patterns of racial segregation" (1986: 114). Hence, it makes sense to study economic segregation within racial groups; otherwise, some of the observed economic segregation will actually be an artifact of the underlying racial basis of residence patterns.

\section{MEASUREMENT OF ECONOMIC SEGREGATION}

To measure economic segregation within racial groups, Erbe and most of the pre-1987 research used the index of residential dissimilarity applied to broad occupational groupings. However, the social meaning and economic status of various occupational categories have changed in ways that make it difficult to compare occupation-based measures over time. One must choose either large numbers of pair-wise dissimilarity indices or a few very broad (perhaps meaningless) groupings of occupations. Farley's work applied the index of dissimilarity to groupings by years of education completed. (He also used the correlation ratio in the same article, which I discuss below.)

More recent work has attempted to use income as the indicator of social class. A prominent example is Massey and Eggers (1990). Census tract data, the basis of almost all segregation studies, report counts of households by income brackets rather than the values for individual households. Massey and Eggers adjusted the 1970 income bracket amounts by the CPI. Since the 1969-79 CPI is 1.98 , or nearly double, these adjusted income categories nearly "lined up" the 1980 income brackets. ${ }^{4}$ They reduced the twelve income categories to four social classes:
Poverty Incomes
$\$ 0-\$ 7,499$
Lower Middle Class
$\$ 7,500-\$ 14,999$;
Upper Middle Class
$\$ 15,000-\$ 29,999$;
Affluent
$\$ 30,000$ and up.

They then computed the six pair-wise indices of dissimilarity. To come up with a final aggregate measure, the average of these six measures is computed $\left(D_{I}\right) \cdot{ }^{5}$ Massey and Eggers concluded that 
interclass segregation among blacks "increased over the 1970's often quite sharply" (1990: 1170). ${ }^{6}$

Whites, Hispanics, and Asians, however, had declines in interclass segregation by this measure.

While ingenious, this method of measuring interclass segregation has a number of problems.

First, the cutoff points between the income classes are arbitrary. Second, income is a continuous variable, and collapsing it into only four categories inevitably loses information. Third, and most important, a measure of dissimilarity based on fixed income cutoffs is not independent of the mean and variance of household income. As the mean and variance change, the class categories "cut" the income distribution at different points. In other words, like $\mathrm{P}^{*}$, the index of dissimilarity used in this way may confound changes in the underlying income distribution with changes in spatial organization.

A simulation will illustrate the problem. Imagine a metropolitan area with 100 neighborhoods. Each neighborhood has 100 households. There is a modest degree of economic segregation. ${ }^{7}$ An increase in the mean of the income distribution, with no change in the variance of income (inequality), will shift households from one class to another, even though they have not moved from one neighborhood to another. If the variance of household income increases, with no change in the mean, some households will shift up in class and others down, again with no spatial movement.

Table 1 shows the effect of such shifts on the $\mathrm{D}_{\mathrm{I}}$ measure. Holding constant the mean level of income, increases in inequality cause the measure of economic segregation to fall even though no household has moved and all households stand in the same relative position in the income distribution. Increases in the mean, holding the standard deviation constant, cause $\mathrm{D}_{\mathrm{I}}$ to rise, though less so at 
TABLE 1

Simulation of Values of $D_{I}$, Under Different Assumptions about the Mean and Variance of the Income Distribution

\begin{tabular}{lcccc}
\hline & \multicolumn{4}{c}{ Standard Deviation of Household Income } \\
\cline { 2 - 5 } Mean Household Income & 10,000 & 15,000 & 20,000 & 25,000 \\
\hline$\$ 20,000$ & 0.57 & 0.49 & 0.44 & 0.41 \\
$\$ 25,000$ & 0.58 & 0.50 & 0.45 & 0.42 \\
$\$ 30,000$ & 0.61 & 0.50 & 0.45 & 0.42 \\
$\$ 35,000$ & 0.67 & 0.52 & 0.47 & 0.43 \\
\hline
\end{tabular}

Note: See text for derivation of values. 
higher income levels. Thus, the index of dissimilarity applied to the income distribution confounds monotonic changes in the income distribution with actual changes in spatial organization. The major source of this problem is that the index of dissimilarity is a measure built around the idea of two welldefined groups. Several authors have developed variations of the index of dissimilarity that can account for more than two groups, but the groups are still expected to be finite in number and well-defined (Sakoda 1981; Morgan and Norbury 1981). James (1986) developed a "generalized segregation index," which extends the reach of exposure-based measures to more than two groups. Income, however, is a continuous variable. Collapsing the distribution into categories throws away information and creates problems of maintaining comparable categories over time.

A counterargument is that income is merely an indicator of social class, which is a polytomous discrete variable. However, the class structure in the United States is too ill-defined and fluid for that really to be true. Moreover, indicators of social class, such as years of education and occupation, change their meaning over time. While income, especially annual income, does have its limitations, it at least measures the relative success of individuals in the labor market and their standing in terms of purchasing power. "Money isn't the only thing," as the saying goes, "but it's pretty far ahead of whatever is in second place."

A segregation measure that is suitable for use with continuous measures is referred to as the "correlation ratio." Farley applied the correlation ratio to years of education to get a "succinct measure" of social-class segregation. He described his method as follows:

Each individual in the sample was assigned a number equaling the years of schooling he had completed. Using these data, we calculated an estimate of the variance of the educational attainment of blacks and whites in the entire urbanized area.... [U]sing the attainment of each person in a tract and the tract mean, we developed a within-tract estimate of the variance in attainment. The correlation ratio, sometimes referred to as eta squared, equals one minus the within tract variance divided by the estimate of variance developed from the total sample (citations omitted). This may be thought of as a one-way analysis of variance model in which the overall variance in socioeconomic status is divided into within census tract and between census tract variances (1977: 503). 
The application to income is straightforward. Each household in a metropolitan area has an income, and the distribution of these incomes has a mean and a standard deviation. Each household is located in space in a neighborhood. Each neighborhood has a mean income, and the distribution of all households by the mean income of their neighborhood also has a mean and a standard deviation. In the unlikely event that all neighborhoods have the same mean income, i.e., there is absolutely no economic segregation between neighborhoods, then the standard deviation of the neighborhood distribution is zero. At the other extreme, if all households live in neighborhoods which have a mean income identical to their own income, than the standard deviation of the neighborhood distribution will be identical to the standard deviation of the household distribution. This measure, which I refer to as the Neighborhood Sorting Index (NSI) is defined as

$$
N S I=\frac{\sigma_{N}}{\sigma_{H}}=\frac{\sqrt{\frac{\sum_{n=1}^{N} h_{n} *\left(\bar{y}_{n}-\bar{y}\right)}{H}}}{\sqrt{\frac{\sum_{i=1}^{H}\left(y_{i}-\bar{y}\right)^{2}}{H}}},
$$

where $y$ is income, $i$ indexes households, $n$ indexes neighborhoods, $h_{n}$ is the number of households in neighborhood $n$, and $H$ and $N$ are the total number of households and neighborhoods respectively. The square of this measure is the between-tract variance over the total variance of household income. Thus, NSI is simply the square root of the correlation ratio applied to income. It is a "pure" measure of economic segregation. It implicitly controls for both the overall income level, because it is based on deviations from the mean household income, and income inequality, since it is expressed as a percentage of total income variance. In contrast to $\mathrm{D}_{\mathrm{I}}$, the Neighborhood Sorting Index is invariant with respect to changes in the mean and variance of household income. 
Farley found that the correlation ratio applied to years of education revealed low levels of socialclass segregation. Similarly, I find that NSI is typically in the range of .40 for whites, implying that the "width" of the neighborhood distribution is only four-tenths the width of the household distribution.

Squaring the figure shows that only about 16 percent of the total variance of household income is between neighborhoods. In other words, economic segregation is relatively low among whites and much of the variance in household income is within neighborhoods. As will be shown below, however, the 1980s saw rapid increases in NSI, especially for blacks.

While theoretically straightforward, estimating NSI involves some complications. The betweentract variance is easy to estimate, since it is merely the household-weighted variance of the neighborhood means. But the total variance of household income is not published by the Census Bureau. Instead, the tract data provide counts of households within broad income brackets, including open-ended top and bottom brackets. Two alternatives exist. One is to use the PUMS individual-level sample data to estimate the variance for each city. However, it is hard to adjust the PUMS data to reflect the geographic adjustments I have made in the tract data to account for metropolitan boundary changes over time. Moreover, the sample is quite thin at the higher levels of income that make large contributions to variance, and the values are top-coded beyond a certain point.

The other method is to use the published counts of households by income bracket and make some assumptions about the distribution of households within income brackets. Based on extensive testing and comparison with PUMS estimates, I assume linear distributions in lower brackets and Pareto distributions in the brackets above the MSA mean. I then take the integral of the appropriate density function times the squared difference from the mean and evaluate it for each bracket. Summing these squared deviations and dividing by the total number of households yields the variance of household income. The details and justifications for the procedures are described in Appendix A. If the number of households for a given racial group in a given MSA is too small, the estimation becomes unstable. ${ }^{8}$ Thus, I only calculate the NSI 
for those racial/ethnic groups with at least 10,000 households (about 35,000 people) in any given metropolitan area.

PATTERNS OF ECONOMIC SEGREGATION: 1970-1990

Table 2 shows the weighted national means for the Neighborhood Sorting Index. Panel A of the table includes all metropolitan areas in the United States that met the data-sufficiency requirement for that group in that year. The number of MSAs is shown. Panel B shows the weighted means, holding the number of cities included constant.

The results show a pronounced trend toward increasing economic segregation. In contrast to Massey and Eggers's findings referenced earlier, NSI rises for whites, blacks, and Hispanics in both decades. ${ }^{9}$ The increases are largest for blacks, for whom NSI increases more than 40 percent between 1970 and 1990. For whites, the NSI increases by about 0.03 in both the 1970s and 1980s. Hispanics have a similar increase in the 1970s, but nearly twice as large an increase in the 1980s. Blacks have a 0.054 increase in the 1970s, but a much larger increase of 0.085 in the $1980 \mathrm{~s}$. These findings are not driven by the inclusion of more MSAs in the later years. As Panel B of Table 2 indicates, inclusion of only those MSAs for which NSI can be calculated in all three years shows a virtually identical pattern of results.

Metropolitan areas usually show incredible diversity, with widely varying levels of and changes over time on most sociodemographic indicators (Frey and Speare 1988). In contrast, the trend toward greater levels of economic segregation was remarkably widespread. In the 1980 s, 108 out of the 111 metropolitan areas for which I calculate a change in NSI had an increase in NSI among blacks. For whites, NSI increased in 253 out of 318 metropolitan areas (79.6 percent); for Hispanics, NSI increased in 39 out of 49 cities (79.6 percent). 
TABLE 2

Neighborhood Sorting Index, 1970 to 1990, Weighted Means

\begin{tabular}{|c|c|c|c|c|c|}
\hline \multirow[b]{2}{*}{ Year } & \multicolumn{2}{|c|}{ White } & \multicolumn{2}{|c|}{ Black } & Hispanic \\
\hline & NSI & MSAs & NSI & MSAs & MSAs \\
\hline
\end{tabular}

Panel A. Metropolitan Areas with 10,000 Households in Given Year

$\begin{array}{llllrrr}1970 & 0.310 & 228 & 0.341 & 76 & 0.384 & 30 \\ 1980 & 0.343 & 318 & 0.395 & 111 & 0.419 & 49 \\ 1990 & 0.374 & 336 & 0.480 & 131 & 0.487 & 68\end{array}$

Panel B. Metropolitan Areas with 10,000 Households in 1970

\begin{tabular}{lllllll}
1970 & 0.310 & 228 & 0.347 & 76 & 0.384 & 30 \\
1980 & 0.351 & 228 & 0.397 & 76 & 0.417 & 30 \\
1990 & 0.385 & 228 & 0.481 & 76 & 0.486 & 30 \\
\hline
\end{tabular}

Note: Means of the metropolitan areas in each cell are weighted by number of households. 
Although the results are weighted by metropolitan area size, they are not driven by a few large cities. Table 3 shows the NSI for metropolitan areas in three broad size classifications. The largest metropolitan areas, those with more than 1 million residents, have higher levels of NSI for whites, blacks, and Hispanics in each decade. The smallest metropolitan areas show very little change in the 1970s, but the pattern of changes in the 1980 s is quite similar to the overall figures. For all size classes, there are increases in the 1980s on the order of 3-4 percentage points for whites and much larger increases for blacks and Hispanics.

Metropolitan economies are embedded in regional economies, and housing market characteristics are also influenced by regional considerations. Hence, it is reasonable to expect that there might be different patterns of outcomes on economic and spatial measures across the various regions. For example, metropolitan areas in different census divisions had very different rates of change on measures of ghetto poverty (Jargowsky 1994). ${ }^{10}$ Figure 1 shows the levels of ghetto poverty for blacks and whites by census division. In the figure, dotted lines connect the white values on NSI for a given year and solid lines connect the black values. ${ }^{11}$ In seven of the nine census divisions, the white NSI value increases modestly in both decades. The exceptions are New England, which shows a slight drop from 1980 to 1990, and the Pacific division, which has a decline from 1970 to 1980. The blacks values show increase for all divisions in both decades; the size of the changes in the 1970s is somewhat variable, but the there are large increases across all nine census divisions in the 1980s. Indeed, by 1990, the values for NSI among blacks were in a class by themselves, standing apart from the values for whites in all years and blacks in earlier years in each division.

In summary, there was a nearly ubiquitous trend toward increases in economic segregation as measured by the Neighborhood Sorting Index. The trend is not an artifact of the addition of new metropolitan areas. Rather, it is characteristic of virtually every region as well as metropolitan areas 
TABLE 3

Neighborhood Sorting Index by Race/Ethnicity and Metropolitan Area Size, 1970 to 1990

\begin{tabular}{|c|c|c|c|}
\hline Year & White & Black & Hispanic \\
\hline \multicolumn{4}{|c|}{ A. MSAs with More Than 1 Million Persons } \\
\hline 1970 & 0.330 & 0.354 & 0.395 \\
\hline 1980 & 0.381 & 0.424 & 0.443 \\
\hline 1990 & 0.413 & 0.500 & 0.512 \\
\hline \multicolumn{4}{|c|}{ B. MSAs with 500,000 to 1 Million Persons } \\
\hline 1970 & 0.278 & 0.301 & 0.369 \\
\hline 1980 & 0.330 & 0.345 & 0.369 \\
\hline 1990 & 0.372 & 0.472 & 0.462 \\
\hline \multicolumn{4}{|c|}{ C. MSAs with less than 500,000 Persons } \\
\hline 1970 & 0.277 & 0.294 & 0.318 \\
\hline 1980 & 0.282 & 0.296 & 0.316 \\
\hline 1990 & 0.312 & 0.398 & 0.376 \\
\hline
\end{tabular}

Note: Size classifications based on 1980 total population. 
Figure 1 here 
of different sizes. For whites, the increases were modest but consistent over time. For blacks and Hispanics, the increases were modest in the 1970s but much larger on average in the 1980s. The rapid increases in economic segregation, especially among blacks, have contributed to ghetto poverty (Wilson 1987; Jargowsky 1991). ${ }^{12}$ Against the backdrop of modest decreases in racial segregation in the 1980s (Farley and Frey 1994; Harrison and Weinberg 1992), these trends suggest that class may in time come to rival race as the organizing principle of the metropolis. To understand whether economic segregation will continue to increase, we need a better understanding of the process driving the current changes. In any case, the changes of the 1980s suggest that it is time to re-evaluate the relative importance of racial and economic segregation.

\section{ECONOMIC SEGREGATION: AN EXPLORATORY CAUSAL MODEL}

This section of the paper develops an exploratory causal model to explain the changes in economic segregation from 1970 to 1990 . Economic segregation is the outcome of a complex series of interacting markets. The first is the labor market, which largely shapes the income distribution and the extent of income inequality, both across and within groups. ${ }^{13}$ Ultimately, however, economic segregation is a drama played out in the housing market. Idiosyncratic features of the urban landscape, such as its physical configuration, room for expansion, accumulated housing stock, and ownership patterns will all affect the degree to which an individual member of a minority group can convert economic achievements into neighborhood status and amenities. Other factors, such as the size of the city, its rate of growth, the degree of pressure on the housing market from immigration, etc., must also be taken into account.

My strategy is to employ a reduced-form, fixed-effects model at the metropolitan level. First, I calculate the changes in NSI for both whites and blacks in the 1970s and 1980s. ${ }^{14}$ These decadal changes are pooled and regressed against a set of dummies for race, decade, and their interaction. ${ }^{15}$ Following the standard path-analytic paradigm (Alwin and Hauser 1975), vectors of variables are added sequentially; 
these vectors correspond to physical context, structural economic transformations, and social distance between whites and blacks. Thus, the basic model is

$$
\begin{aligned}
\Delta \text { NSI }_{\mathrm{mrd}}= & \mathrm{f}\left(\text { BLACK }_{\mathrm{mdr}}, \text { EIGHTIES }_{\mathrm{mdr}}, \text { PHYSICAL CONTEXT }_{\mathrm{md}},\right. \\
& \text { ECONOMIC TRANSFORMATION } \left._{\mathrm{md}}, \text { SOCIAL DISTANCE }_{\mathrm{mdr}}\right)
\end{aligned}
$$

where

$$
\begin{aligned}
& \text { NSI = Neighborhood Sorting Index } \\
& \mathrm{m}=\text { MSA }, \quad \mathrm{d}=\text { Decade }, \quad \mathrm{r}=\text { Race }
\end{aligned}
$$

The variables in each vector, the hypotheses they are meant to test, and the expected signs of the coefficients are discussed briefly below.

Physical Context. Many features of metropolitan labor and housing markets can be expected to affect the extent to which high- and low-income blacks and/or whites will be segregated from one another. To the extent that such features are common to individual metropolitan areas and invariant between 1970 and 1990, the fixed-effects structure of my model controls for them implicitly.

Other features may be correlated with region, hence a set of dummies for census division is included in the regressions. Larger metropolitan areas would be expected to encompass greater differentiation of neighborhoods (White 1987), and so sheer size (measured at the beginning of the decade) should have a positive effect on economic segregation. A rapid influx of new households would put pressure on the housing market and, in the short run at least, reduce economic segregation. ${ }^{16}$ This effect is represented by the percentage of MSA residents ages five or older who lived outside the MSA five years before the base year of the decade (i.e., 1965 or 1975); a negative effect is expected. I also include the percentage change in total population over the decade, which includes both immigration and native population growth. The overall income level at the beginning of the decade is also entered as a contextual variable. 
Structural Economic Transformations. The economic restructuring that is having such a profound impact on other aspects of urban spatial structure may also affect economic segregation within racial groups. A smaller share of jobs in manufacturing, greater dispersion of jobs from the urban core, and changing returns to skill levels may play a role in increasing inequality. These factors may also affect economic segregation by drawing the more skilled blacks out of traditional minority enclaves to servicesector jobs in dispersed locations. Specifically, decreases in manufacturing might be expected to encourage greater levels of economic segregation as newer firms locate in a more dispersed pattern with concurrent adjustments in employee residence patterns. Thus, the expected sign on percentage of jobs in manufacturing is negative.

Increasing skill demands, reflected in the percentage of jobs in professional and managerial occupations, could accentuate social class differences within racial groups, decrease group cohesion, and lead to increases in economic segregation within the black and white communities (Wilson 1980). A high proportion of professionals and managers would also reflect knowledge-based firms with greater freedom to decentralize. Hence, the expected sign for proportion of jobs in professional and managerial occupations is positive.

Changes in Social Distance. The literature on racial segregation generally supports the hypothesis that social distance between groups will be translated into physical distance (Massey 1981). What is less clear is how the social distance between groups will affect the economic segregation within a group. A plausible hypothesis is that greater social distance between groups will lead to greater constriction of the housing options of all members of the lower-status group—guilt by association—and hence, less economic segregation of members of that group. In turn, increasing economic success within the lower-status group will lead to racial assimilation of the more advantaged members of that group, increasing their ability to separate themselves from lower-status members (Wilson 1987; Hughes 1989). Thus, decreases in social distance between blacks and whites should translate into increases in economic segregation within the black community. 
Many of the expected signs I predict could be debated, especially in the context of the reducedform models I estimate. Suffice it to say that two-tailed tests will be employed throughout.

Data and Regression Results. The data in these regressions are drawn from a variety of sources. Tract data used to compute racial and economic segregation measures come from the 1970 Fourth Count File A, 1980 Summary Tape File 4A, and 1990 Summary Tape File 3A (CD ROM version). The 1980 data were adjusted to correct for the effects of complementary suppression. ${ }^{17}$ Metropolitan-level variables were taken from the "C" versions of these files. To the extent possible, I have adjusted for changes in metropolitan boundaries, which were extensive. ${ }^{18}$

The weighted regression results are shown in Table $4 .{ }^{19}$ Model A includes only dummies for black and decade, and the interaction of these two. The constant in this regression represents the component of increase in economic segregation common to whites and blacks in both decades: an increase of 3.6 percentage points. In this simple model, there was no significant difference between blacks and whites until the 1980s, when the economic segregation of blacks increased by 5.4 percentage points over and above the common increase. Of course, the black dummy variable is merely a proxy for some factor or factors in the process of generating economic segregation that particularly affects blacks. In a complete model, which included all relevant variables, one would expect the coefficient on the black dummy variable to be driven to zero, i.e., that the black/white differential would be fully explained.

Model B adds variables to account for the geographic and spatial context of the metropolitan area. A set of dummies for census division (the omitted category is Pacific) captures features of metropolitan housing markets and economic structure that vary by region. ${ }^{20}$ These are all significant or nearly so, and positive; implying larger increases in economic segregation than the Pacific states, 
TABLE 4

Decadal Changes in Economic Segregation: Pooled Regression Results, 1970-1990

Dependent Variable: Change in Neighborhood Sorting Index over Decade

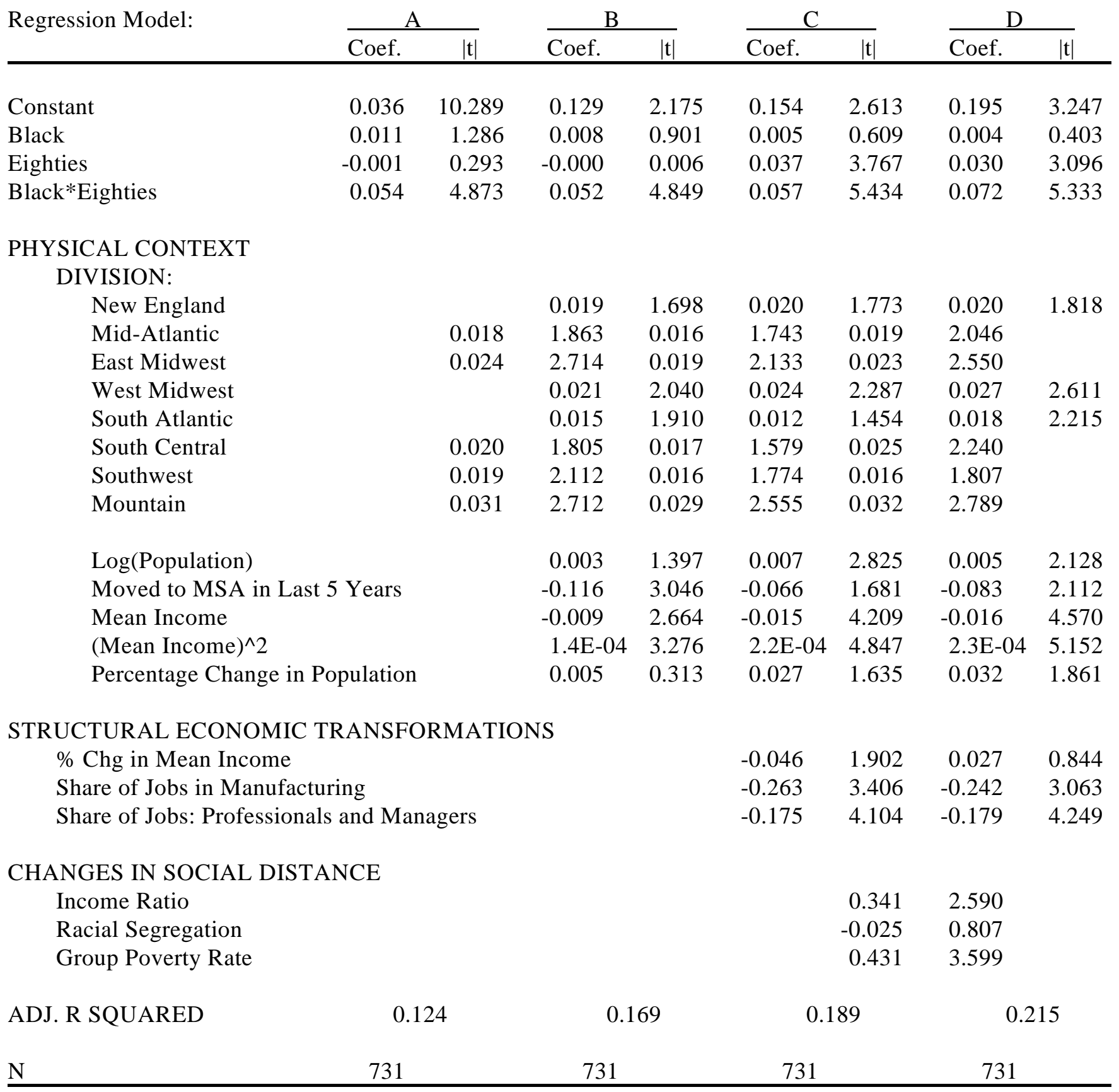


especially in the Mountain states and the Midwest. As expected, cities with higher proportions of immigrating residents had smaller increases in NSI. The relative wealth of an MSA, measured in the base year, also affected the change in economic segregation over the decade, but in a nonlinear fashion. ${ }^{21}$

Interestingly, the introduction of these variables has virtually no impact on the level or significance of the three dummy variables in Model A. The spatial and geographic context cannot explain the fact that blacks had such dramatic increases in economic segregation in the 1980s relative to whites and blacks in the 1970 s.

Model C introduces several broad proxies for structural economic transformations. The effect of the change in mean income over the decade, unlike the level of mean income entered above, does not have a significant effect on economic segregation. However, the change in the share of jobs in manufacturing does have a significant effect in the expected direction. Declines in manufacturing are associated with increases in economic segregation, even after controlling for an MSA's income level at the beginning of the decade and the change in income over the decade.

Increasing skill levels, proxied by the change in the share of jobs in professional or managerial occupations, also has a significant coefficient, but the effect is opposite the direction anticipated. One would have thought that more managerial and professional jobs would serve to emphasize class distinctions and encourage segregation along social class lines. One possible explanation is that the increase in managerial and professional jobs leads to an increase in economic inequality. Since jobs and annual income probably can change faster than the housing market, the negative coefficient may reflect a disequilibrium condition. If the overall variance of household income changes faster than persons can change neighborhoods to reflect their new status, the between-neighborhood proportion of that variance may temporarily dip. This topic merits further research, preferably with longitudinal data.

Once again, the coefficient of Black*Eighties is not explained by the addition of the new variables. It actually increases slightly. And the coefficient on the dummy variable for the 1980s, formerly zero, increases to 3.7 percentage points and becomes statistically significant! The implication is that there is an 
unexplained increase of nearly 4 percentage points, common to whites and blacks, in the 1980s relative to the 1970s. Thus, if there had been no structural economic transformations (or at least no changes in the variables I have included as proxies), the increases in economic segregation would have been even greater than they were.

Finally, Model D adds the proxies for social distance. "Income ratio" represents the change in the ratio of the group's (i.e., white or black) mean income to the MSA mean. The coefficient is positive, the expected direction. Improvements in social status relative to the metropolitan mean lead to increases in economic segregation. "Racial segregation" represents the change in the ratio of dissimilarity of whites from blacks. While the coefficient has the expected sign, it is insignificant.

"Group Poverty Rate" represents the change in the proportion of the group (white or black) falling below the federally defined poverty line. This measure, the only one entered in the regression that reflects within-group differences, is positive and significant. Increases in poverty within the group thus contribute to increased spatial segregation, supporting the hypothesis of middle-class flight (Wilson 1987).

Since the social distance measures might be expected to enter into the relationship very differently for whites and blacks, I estimated a regression in which the social distance coefficients were allowed to vary, by interacting them with the black dummy variable. Surprisingly, the coefficients on the interaction terms were all insignificant and their inclusion caused virtually no change in the size or significance of the other coefficients in the regression. ${ }^{22}$

The social distance measures also fail to explain why the 1980 s were different, especially for blacks. Indeed, after including the social distance proxies, the coefficient on Black*Eighties increased yet again, to 7.2 percentage points. The coefficient on the Eighties dummy variable decreased only slightly, to 3.0 percentage points. In contrast, the black dummy variable decreased in value and significance each time new variables were added. The changes in economic segregation among blacks and whites in the 1970s followed a similar course, but in the 1980s were radically different. This large residual difference must reflect either a fundamental change in the nature of the relationship or large changes in the 1980s in 
some variable not well controlled in this regression. Further research into this phenomenon is clearly warranted.

\section{CONCLUSION}

In the spatial and economic organization of metropolitan areas, households get sorted along a number of important dimensions. Among them are:

- The spatial segregation of racial and ethnic groups from each other, usually measured by D;

- General economic inequality, either overall or within racial groups, which is nonspatial;

- The spatial segregation of social and economic groups from each other;

- The segregation of racial groups from one another, after controlling for income or social class, which measures the degree to which spatial assimilation follows from economic assimilation ("direct standardization");

- The segregation of economic groups from one another, controlling for racial group, i.e., economic segregation within race, which bears on such issues as the "flight of black middle class" proposed by Wilson, and which is measured by $\mathrm{D}_{\mathrm{I}}, \mathrm{NSI}$, and similar measures.

In this paper, I have primarily discussed the last of these dimensions, economic segregation within racial and ethnic groups. I have argued that the NSI measure defined herein, which is closely related to the correlation ratio used in previous studies, is a particularly appropriate measure for studying economic segregation. Unlike the index of dissimilarity, it is well suited for use with a continuous variable like income. NSI also gives a pure measure of the degree of residential segregation of households with different levels of income after controlling for the mean level of income and the amount of inequality. Unlike the index of dissimilarity applied to several income classes (Massey and Eggers 1990), NSI is not sensitive to changes in the parameters of the income distribution per se, only to movements of households from one neighborhood to another. 
NSI demonstrates a steady trend of increases in economic segregation. For blacks and Hispanics, however, the growth in economic segregation is particularly acute in the 1980s. Increases in economic segregation were nearly ubiquitous, with few metropolitan areas bucking the trend. It affected big cities and small alike across all regions of the United States. Given the tremendous variation among metropolitan areas in terms of economic bases, housing market characteristics, poverty trends, etc., the broad nature of these changes suggests that a fundamental and important process is under way. To understand the future of America's cities, we will need to have a better understanding of the mechanisms driving economic segregation. 


\section{APPENDIX A}

\section{Calculation of the Variance of Household Income}

The variance of household income is not available directly in tract-level census data. Rather, one has a count of households in different income brackets. To estimate the variance of household income from this data, some assumption must be made about the distribution of household incomes within the brackets. I have made linear interpolations of households for all brackets below or containing the metropolitan mean income. While a log normal distribution is sometimes assumed for the lowest bracket, my inspection of the actual distributions led me to reject that approach. ${ }^{23}$ For income brackets with lower bounds in excess of the metropolitan mean income, I assume a Pareto distribution, with separate parameters allowed in each bracket subject to a continuity constraint. For the open-ended top bracket, the slope of the Pareto distribution is assumed to be the same as the next-to-last bracket. ${ }^{24}$

The Pareto Distribution is given by:

$$
N=\alpha Y^{\beta}
$$

where $\mathrm{N}$ is the number of households with incomes of $\mathrm{Y}$ or greater, and $\alpha$ and $\beta$ are estimable parameters. Taking logs results in a linear form, which allows a simple point-to-point calculation of the parameters for each bracket, as follows (Cloutier 1988):

$$
\begin{gathered}
\ln (N)=\ln (\alpha)+\beta \ln (Y) \\
\beta_{b}=\frac{\ln \left(N_{b+1}\right)-\ln \left(N_{b}\right)}{\ln \left(Y_{b+1}\right)-\ln \left(Y_{b}\right)} \quad \alpha_{b}=\frac{N_{b}}{Y^{\beta_{b}}}
\end{gathered}
$$


The Pareto Distribution, as written above, is in a cumulative form from the top, i.e., the highest income (Miller 1971). Rewriting the function as $(\mathrm{P}-\mathrm{N})$, where $\mathrm{P}$ is a constant representing the total population, makes the function cumulative from the origin. Hence, the associated density function is the first derivative of the reversed distribution:

$$
\begin{aligned}
& F(y)=P-N=P-\alpha Y^{\beta} \\
& f(y)=\frac{d F(y)}{d Y}=-\alpha \beta Y^{\beta-1}
\end{aligned}
$$

To estimate the variance, we first need the sum of the squared deviations of all households from the overall metropolitan mean. Rather than simulate individual households, which is time consuming even with a fast computer, I make use of the following integral for calculating the sum of the squared deviations from the mean:

$$
\sum_{i=1}^{n_{b}} \delta^{2}=\int_{L}^{U}(y-\bar{y})^{2} f(y) d y
$$

where $\mathrm{n}_{\mathrm{b}}$ is the number of households in income bracket $\mathrm{b}$, indexed by $\mathrm{i}$; $\mathrm{L}$ and $\mathrm{U}$ are the lower and upper limits of the income bracket, and $\mathrm{Y}$ bar is the mean income of the metropolitan area. Substituting from equation 3 and manipulating terms yields:

$$
\begin{aligned}
\sum_{i=1}^{n_{b}} \delta_{i}^{2} & =-\alpha \beta \int_{L}^{U}\left(y^{2}-2 \bar{y} y+\bar{y}^{2}\right) y^{\beta-1} d y \\
& =-\alpha \beta \int_{L}^{U}\left(y^{\beta+1}-2 \bar{y} y^{\beta}+\bar{y}^{2} y^{\beta-1}\right) d y \\
& \left.=-\alpha \beta\left(\frac{1}{\beta+2} y^{\beta+2}-\frac{2 \bar{y}}{\beta+1} y^{\beta+1}+\frac{\bar{y}^{2}}{\beta} y^{\beta}\right)\right]_{L}^{U}
\end{aligned}
$$


The expression is defined as long as $\beta$ is not equal to $-2,-1$ or zero. For the open-ended top bracket, the integral converges to zero as long as $\beta$ is less than -2 , which is the case for all large metropolitan areas.

For the remaining brackets, a simple linear interpolation is used. Obviously, the mean of the incomes in the bracket is the midpoint of the bracket. But the sum of the squared deviations is not the same as the squared deviation of the mean income times the number of households. Again, an integral over the appropriate area solves the problem:

$$
\begin{aligned}
\int_{L}^{U}(y-\bar{y}) f(y) d y & =\int_{L}^{U}\left(y^{2}-2 \bar{y} y+\bar{y}^{2}\right) \frac{n_{b}}{U-L} d y \\
& =\frac{n_{b}}{U-L}\left[\frac{y^{3}}{3}-\bar{y} y^{2}+\bar{y}^{2} y\right]_{L}^{U}
\end{aligned}
$$

The sums of the squared deviations from the metropolitan mean are added across brackets and divided by the number of households to derive the variance of household income. 


\section{Endnotes}

${ }^{1}$ The quote is from the Introduction, by Nathan Glazer, as cited by Erbe.

${ }^{2} \mathrm{I}$ am assuming here that income increases without any change in occupation or education level of adult workers, which are the two measures used by Erbe to indicate social class.

${ }^{3}$ In a similar vein, Miller and Quigley, using the entropy measure of residential segregation, concluded that "only a small fraction...of segregation by race can be explained by economic forces leading to a clustering by demographic group" (1990: 17-18).

${ }^{4}$ To the extent that these brackets did not line up, Massey and Eggers moved households from one category to another by linear interpolation.

${ }^{5} \mathrm{~A}$ somewhat simpler approach is to calculate the index of dissimilarity for the poor vs. the nonpoor (Abramson and Tobin 1994).

${ }^{6}$ It should be noted, however, that Massey and Eggers found no evidence that these increases in economic segregation played a role in the increases in the isolation of the black poor as Wilson (1987) and Jargowsky (1991) have claimed.

${ }^{7}$ The economic segregation is generated by a random process in which income is determined by a random normal deviate and spatial location is determined by two random normal deviates, one of which is retained from the income determination. Households are ordered on the location index and each group of 100 households constitutes a neighborhood.

${ }^{8}$ In particular, the estimation of the MSA-level parameters of the Pareto distribution in the uppermost income brackets begins to yield improbable values when too few households are included in the calculation.

${ }^{9}$ These findings are consistent with those of Abramson and Tobin (1994), who find a pattern of increases in the Index of Dissimilarity of the poor from the nonpoor. However, their findings are not reported separately by race. 
${ }^{10}$ Census "divisions" are subunits of the broader classification of census "regions." There are nine divisions in all: New England; Middle Atlantic; East North Central; West North Central; South Atlantic; East South Central; West South Central; Mountain; and Pacific.

${ }^{11}$ For Hispanics, there were too few metropolitan areas for which I was able to calculate values of NSI to allow sub-division by census divisions.

${ }^{12}$ For a contrary view see Massey and Eggers (1990) and Massey, Gross, and Shibuya (1994).

${ }^{13}$ Obviously, there are other sources of income such as passive earnings on assets, public assistance, etc., which also contribute to the income distribution.

${ }^{14}$ Hispanics are omitted from consideration owing to data limitations.

${ }^{15}$ Technically, this dependent variable violates the Gauss-Markov assumptions because it is a restricted range variable. The least it can be is -1.00 and the greatest it can be is +1.00 . I rescaled the variable to a $[0,1]$ range and repeated all regressions after performing the standard logit transformation. Since no metropolitan areas come near the extremes of this range, the transformation has virtually no effect on the relative size of the coefficients or their statistical significance. I present the untransformed regressions in the text because the coefficients are easier to interpret.

${ }^{16}$ Note that this is a disequilibrium condition. In the longer run, the increased demand in the housing market could lead to new construction which might create greater opportunities for the rich to segregate from the poor (Cadwallader 1992: 155).

${ }^{17}$ See Jargowsky (1991: Appendix A) for details.

${ }^{18}$ See Jargowsky (1994) for details of the geographic adjustments made. See also Littman (1991).

${ }^{19}$ To deal with possible heteroskedasticity due to differences in the number of households by metropolitan areas, the regressions are weighted by the square root of the number of households entering into the calculation of NSI (Maddala 1977: 268).

${ }^{20}$ Metropolitan areas that span boundaries of two or three census divisions were recoded to the 
division with the largest share of the area's total population.

${ }^{21}$ The point of inflection is about $\$ 32,000$ in all the models. At the income levels lower than this, income is negatively related to changes in economic segregation. At income levels above that point, they are positively related.

${ }^{22}$ Regression not shown. An F test failed to reject the restriction of equal slopes on the social distance variables. In contrast, all other groups of variables added above made statistically significant contributions to $\mathrm{R}^{2}$.

${ }^{23}$ The lower tails were too chaotic, with the second bracket sometimes larger, sometimes smaller than the first. A larger first bracket is inconsistent with log-normal distribution, unless of course that bracket contains the median.

${ }^{24}$ Recall that in a classic Pareto Distribution, the parameters of all the top brackets would be expected to be the same since there would be only one set of parameters. 


\section{References}

Abramson, Alan J., and Mitchell S. Tobin. 1994. "The Changing Geography of Metropolitan Opportunity: The Segregation of the Poor in U.S. Metropolitan Areas, 1970 to 1990." Fannie Mae Annual Housing Conference, 1994. Washington, D.C.: Fannie Mae Office of Housing Research.

Alwin, Duane F., and Robert M. Hauser. 1975. "The Decomposition of Effects in Path Analysis." American Sociological Review, 40: 37-47.

Cadwallader, Martin. 1992. Migration and Residential Mobility: Macro and Micro Approaches. Madison: University of Wisconsin Press.

Cloutier, Norman R. 1982. "Urban Residential Segregation and Black Income." Review of Economics and Statistics, 64: 282-288.

. 1988. "Pareto Extrapolation Using Grouped Income Data." Journal of Regional Science, 28 (No. 3): 415-419.

Erbe, Brigitte Mach. 1975. "Race and Socioeconomic Segregation." American Sociological Review, 40: $801-812$.

Farley, Reynolds. 1977. "Residential Segregation in Urbanized Areas of the United States in 1970: An Analysis of Social Class and Racial Differences." Demography 14 (No. 4): 497-517. 1984. Blacks and Whites: Narrowing the Gap? Cambridge, Mass.: Harvard University

Press.

. 1991. "Residential Segregation of Social and Economic Groups among Blacks, 1970 to

1980." In Christopher Jencks and Paul E. Peterson, eds., The Urban Underclass. Washington, D.C.: The Brookings Institution, pp. 274-294.

Farley, Reynolds, and William H. Frey. 1994. "Changes in the Segregation of Whites from Blacks during the 1980s: Small Steps toward a More Integrated Society." American Sociological Review, 59 (February): 23-45. 
Frey, William H., and Alden Speare, Jr. 1988. Regional and Metropolitan Growth and Decline in the United States. New York: Russell Sage Foundation.

Harrison, Roderick J., and Daniel Weinberg. 1992. "Changes in Racial and Ethnic Segregation." Paper prepared for the American Statistical Association Meetings, Boston (August).

Hughes, Mark Alan. 1987. "Moving Up and Moving Out: Confusing Ends and Means about Ghetto Dispersal." Urban Studies, 24: 503-517. . 1989. "Misspeaking Truth to Power: A Geographical Perspective on the 'Underclass' Fallacy." Economic Geography, 65 (No. 3): 187-207. .1991. "Employment Decentralization and Accessibility: A Strategy for Stimulating Regional Mobility." Journal of the American Planning Association, Summer, pp. 288-298. Hughes, Mark, and Janice Fanning Madden. 1990. "Residential Segregation and the Economic Status of Black Workers: New Evidence for an Old Debate." Journal of Urban Economics, 29: 28-49. James, Franklin J. 1986. "A New Generalized `Exposure-Based’ Segregation Index： Demonstration in Denver and Houston." Sociological Methods and Research, 14 (No. 3): 301-316.

Jargowsky, Paul A. 1991. Ghetto Poverty: The Neighborhood Distribution Framework. Cambridge, Mass.: Malcolm Wiener Center for Social Policy (John F. Kennedy School of Government, Harvard University), Dissertation Series, \#D-91-4. . 1994. "Ghetto Poverty among Blacks in the 1980s." Journal of Policy Analysis and Management, 13 (No. 2, Spring): 288-310.

Kain, John F. 1986. "The Influence of Race and Income on Racial Segregation and Housing Policy." In John M. Goering, ed., Housing Desegregation and Federal Policy. Chapel Hill, N.C.: University of North Carolina Press.

Kantrowitz, Nathan. 1973. Ethnic and Racial Segregation in the New York Metropolis. New York: Prager. 
Littman, Mark S. 1991. "Poverty Areas and the 'Underclass': Untangling the Web." Monthly Labor Review, March, pp. 19-32.

Maddala, G. S. 1977. Econometrics. New York: McGraw-Hill.

Massey, Douglas S. 1981. "Social Class and Ethnic Segregation: A Reconsideration of Methods and Conclusions." American Sociological Review, 46: 641-650.

Massey, Douglas S., and Nancy A. Denton. 1987. "Trends in the Residential Segregation of Blacks, Hispanics, and Asians: 1970-1980." American Sociological Review, 52: 802-825. . 1988a. "The Dimensions of Racial Segregation." Social Forces, 67 (No. 2): 281-315. . 1988b. "Suburbanization and Segregation in U.S. Metropolitan Areas." American Journal of Sociology, 94 (No. 3): 592-626. . 1989. "Hypersegregation in U.S. Metropolitan Areas: Black and Hispanic Segregation along Five Dimensions." Demography, 26 (No. 3): 373-391.

Massey, Douglas S., and Mitchell L. Eggers. 1990. "The Ecology of Inequality: Minorities and the Concentration of Poverty, 1970-1980." American Journal of Sociology, 95 (No. 5): 1153-1188. Massey, Douglas S., Andrew B. Gross, and Kumiko Shibuya. 1994. "Migration, Segregation, and the Geographic Concentration of Poverty." American Sociological Review, 59 (June): 425-445. Miller, Herman P. 1971. Rich Man, Poor Man. New York: Crowell. Miller, Vincent P., and John M. Quigley. 1990. "Segregation by Racial and Demographic Group: Evidence from the San Francisco Bay Area." Urban Studies, 27, (No. 1): 3-21.

Morgan, B. S., and J. Norbury. 1981. "Some Further Observations on the Index of Residential Differentiation." Demography, 18 (No. 2): 251-256.

Park, Robert E. 1926. "The Urban Community as a Spatial Pattern and a Moral Order." In E. W. Burgess, ed., The Urban Community. Chicago: University of Chicago Press.

Sakoda, J. M. 1981. "A Generalized Index of Dissimilarity." Demography, 18 (No. 2): 245-250. 
U.S. Bureau of the Census. 1992. Studies in the Distribution of Income. Current Population Reports, Series P60-183. Washington, D.C.: U.S. Government Printing Office. 1993. Money Income of Households, Families, and Persons in the United States: 1992.

Current Population Reports, Series P60-184. Washington, D.C.: U.S. Government Printing Office.

White, Michael J. 1987. American Neighborhoods and Residential Differentiation. New York: Russell Sage Foundation. (Census Monograph Series.)

Wilson, William Julius. 1980. The Declining Significance of Race: Blacks and Changing American Institutions, 2nd Ed. Chicago: University of Chicago Press. 1987. The Truly Disadvantaged: The Inner City, the Underclass, and Public Policy. Chicago: University of Chicago Press.

Winship, Christopher. 1977. "A Revaluation of Indexes of Residential Segregation." Social Forces, 55 (No. 4): 1058-1066. 